\title{
BMJ Open Characteristics of older adults with back pain associated with choice of first primary care provider: a cross-sectional analysis from the BACE-N cohort study
}

\author{
Ørjan Nesse Vigdal (D , ${ }^{1}$ Kjersti Storheim, ${ }^{1,2}$ Rikke Munk Killingmo, ${ }^{1}$ \\ Milada Cvancarova Småstuen, ${ }^{1}$ Margreth Grotle (D) ${ }^{1,2}$
}

\begin{abstract}
To cite: Vigdal øN, Storheim K,
Munk Killingmo R, et al. Characteristics of older adults with back pain associated with choice of first primary care provider: a cross-sectional analysis from the BACE-N cohort study. BMJ Open 2021;11:e053229. doi:10.1136/ bmjopen-2021-053229
\end{abstract}

- Prepublication history and additional supplemental material for this paper are available online. To view these files, please visit the journal online (http://dx.doi.org/10.1136/ bmjopen-2021-053229).

Received 08 May 2021 Accepted 06 September 2021

Check for updates

(c) Author(s) (or their employer(s)) 2021. Re-use permitted under CC BY-NC. No commercial re-use. See rights and permissions. Published by BMJ.

${ }^{1}$ Department of Physiotherapy, Oslo Metropolitan University,

Oslo, Norway

${ }^{2}$ Research and Communication Unit for Musculoskeletal Health, Oslo University Hospital, Oslo, Norway

Correspondence to Dr Ørjan Nesse Vigdal; orvig@oslomet.no

\section{ABSTRACT}

Objectives To describe characteristics of older adults with back pain in primary care, and to assess associations between patient characteristics and type of first primary care provider (general practitioner (GP), physiotherapist (PT) or chiropractor).

Design Cross-sectional analysis from the Back Complaints in the Elders-Norway cohort study.

Setting Norwegian GP, PT and chiropractic primary care centres.

Participants Patients aged $\geq 55$ years seeking Norwegian primary care with a new episode of back pain were invited to participate. Between April 2015 and February 2020, we included 452 patients: 127 first visited a GP, 130 first visited a PT and 195 first visited a chiropractor.

Primary and secondary outcome measures For the first objective, the outcome measure was descriptive statistics of patient characteristics, covering the following domains: sociodemographic, general health, current and previous back pain, psychological and clinical factors. For the second objective, first primary care provider was the outcome measure. Associations between patient characteristics and visiting a GP or PT compared with a chiropractor were assessed with multiple multinomial regression analyses.

Results Median (IQR) age was 66 (59-72) years. Levels of back-related disability was moderate to severe, with a median (IQR) Roland-Morris Disability Questionnaire (range 0-24) score of 9 (5-13). Recurring episodes were common, 301 (67\%) patients had monthly or yearly recurrences. Patients with worse back-related disability, longer duration of symptoms, lower expectations for full recovery and worse physical performance measured with the Back Performance Scale had higher odds of visiting a GP or PT compared with a chiropractor $(p<0.05)$.

Conclusion Older back pain patients in primary care had moderate to severe levels of back-related disability, and most had recurring episodes. Our results suggest that older adult's choice of first primary care provider was associated with important patient characteristics, which highlights the need for caution with generalisations of study results across primary care populations.

Trial registration number NCT04261309.

\section{INTRODUCTION}

Back pain is the number one cause of years lived with disability globally, with an estimated
Strengths and limitations of this study

- We used descriptive statistics to provide a thorough presentation of characteristics of older people seeking primary care for a new episode of back pain.

- This study used multivariate, multinomial regression analyses to provide a comprehensive overview of associations between patient characteristics and choice of first healthcare provider.

- It was not possible to obtain data on eligible patients that were not invited or declined to participate in the study, which might reduce external validity.

- Due to differences in primary care organisation between countries, readers are advised to exercise caution with generalisations of results to other healthcare systems.

point prevalence of $11.9 \% .{ }^{12}$ Older adults have historically been under-represented in back pain research, ${ }^{34}$ but have recently received increased attention. ${ }^{5}{ }^{6}$ Although the prevalence of pathoanatomical findings on diagnostic imaging increases with age, ${ }^{7-9}$ the prevalence of serious pathology, such as vertebral fractures and neuropathic pain in older back pain patients in primary care is low. Studies have reported a prevalence of $6 \%$ and $2 \%-11 \%$, respectively. ${ }^{1011}$ Moreover, studies in primary care have found significant national differences in the characteristics and burden of back pain in older adults. ${ }^{12} 13$ This highlights the importance of caution when generalising results from studies from one setting to another.

Most patients seeking healthcare for back pain are treated in primary care. ${ }^{14}$ In Norway, back pain is the reason for $10 \%$, $27 \%$ and $86 \%$ of the visits to general practitioners (GP), physiotherapists (PT) and chiropractors, respectively. ${ }^{15}$ Some studies suggest that choice of first primary care provider has consequences for future 
healthcare consumption, including imaging and opioid use. ${ }^{16} 17$ To optimise decision making regarding treatment, research and health policies, detailed knowledge of patient populations is required. Most of the previous studies exploring patient populations seeking primary care have compared GP and chiropractic populations, showing that patients seeking care from a GP have a higher overall burden of back pain compared with chiropractic patients. ${ }^{18-25}$ Only a few studies include PT populations. $^{26-29}$ These studies suggest that patients seeking care from PTs are older and have more disability than those seeking care from chiropractors. ${ }^{26} 2729$ To the best of our knowledge, only one study has been performed in an exclusively older population. ${ }^{28}$ This study found that older women seeking care from GPs reported worse back pain and worse health-related quality of life (HR-QoL) than older women visiting a PT or a chiropractor. ${ }^{28}$ The study only included women between 59 and 64 years of age, and it is not clear if the results are also generalisable to men or adults over 65 years of age. Further, they did not examine back-related disability or other back pain factors, sociodemographic factors, psychological factors or clinical factors. Thus, there is still a considerable lack of knowledge regarding whether characteristics of older back pain patients differ according to their choice of first primary care provider.

Therefore, the aims of this study were (1) to describe the characteristics of patients $\geq 55$ years of age seeking primary care for a new episode of back pain in terms of sociodemographic, general health, current back pain and back pain history, psychological and clinical characteristics and (2) to assess if patient characteristics are associated with type of first primary care provider (GP, PT or chiropractor).

\section{METHODS}

\section{Design and setting}

This cross-sectional study presents baseline data from the Back Complaints in the Elders-Norway (BACE-N) study, a prospective observational cohort study in Norwegian primary care. The BACE-N study is a part of the international BACE consortium, with research groups from Brazil, the Netherlands and Australia. ${ }^{6}$

Norwegian primary care is organised by the municipalities and financed through the National Insurance Scheme, the municipalities and patient copayment. ${ }^{30}$ There is direct access to GPs, PTs (from 2018) and chiropractors. ${ }^{30}$ Patient copayment rates vary between healthcare providers, with chiropractors generally having the highest copayment cost. ${ }^{30}$ Treatments provided usually differ between the healthcare providers. For example, patients visiting a GP are more likely to receive pharmacological therapy, patients visiting a PT are more likely to receive exercise therapy, and patients visiting chiropractors are more likely to receive manipulation therapy. ${ }^{15}$

\section{Participants and recruitment procedure}

Eligible patients were $\geq 55$ years of age, seeking primary care from a GP, PT or chiropractor in primary care for a new episode of back pain. Back pain was defined as pain located in the region from the top of the scapula to the sacrum, with or without radiating leg pain. A new episode was defined as not having received healthcare for the same complaint in the last 6 months. Patients were excluded if they had difficulties completing the questionnaire due to language barriers, or if they had difficulties completing the clinical examination (eg, wheelchair-bound patients). Participants received care as usual.

Patients were recruited from GPs, PTs and chiropractors in urban and rural parts of Norway between April 2015 and February 2020, either during or immediately after the consultation. The primary care providers were instructed to invite consecutive patients. To facilitate the recruitment process, media advertisements were also used. Eligible patients received oral and written information about the study. The final screening for eligibility and inclusion to the study was performed by the researchers. All included patients signed an informed consent form before enrolment in the study. The baseline measurements, consisting of questionnaires and a clinical examination, were collected as soon after the first primary care consultation as possible.

\section{Measurements}

\section{Sociodemographic variables}

Information regarding age, sex, marital status, employment status and educational level was collected.

\section{General health variables}

HR-QoL was measured using the Short-Form Health Survey 36-item physical and mental summary measures (standardised with a mean of 50 and an SD of 10 according to a general US population with higher scores denoting better health). ${ }^{31}$ Alcohol consumption was measured using the three-item Alcohol Use Disorder Identification Test consumption questions (AUDIT-C) (range 0-12, higher score indicates higher alcohol consumption) ${ }^{32}$ Hazardous alcohol consumption was defined as an AUDIT-C score of $\geq 3 / 12$ for women and $\geq 4 / 12$ for men. ${ }^{33}{ }^{34}$ Smoking status (current smoker, previous smoker, non-smoker) was collected. The number of comorbidities was measured using the Self-Administered Comorbidity Questionnaire (SCQ). ${ }^{35}$ The SCQ has 13 predefined comorbidities and two optional comorbidities. Item 12, 'back pain', was replaced with a third optional comorbidity. Widespread pain was measured using the pain drawing from McGill Pain Questionnaire and the revised criteria from Wolfe et al for widespread pain. ${ }^{3637}$ The number of falls during the last 6 weeks was collected, and falls self-efficacy was measured using the Falls Efficacy Scale-International (range 16-64, higher score indicated lower falls efficacy). ${ }^{38}$

\section{Current back pain and back pain history variables}

Back pain location (thoracic or lumbar, or both) was collected. Average back pain severity last week was 
measured using the Numeric Rating Scale (range 0-10, higher score indicates higher back pain severity). ${ }^{39}$ Backrelated disability was measured with the 24-item RolandMorris Disability Questionnaire (RMDQ) (range 0-24, higher score indicated more back-related disability). ${ }^{40}$ Back pain duration was measured in days and categorised into ' $<6$ weeks', ' 6 weeks to 3 months' and ' $>3$ months'. Frequency of previous back pain episodes (monthly, yearly, every $1-5$ years, every 5 years, once) was collected. Sleep problems attributable to back pain were measured using item 5i from the Pittsburgh Sleep Quality Index, ${ }^{41}$ and dichotomised to 'weekly/less than weekly'. Morning stiffness was measured with item six from Knee injury and Osteoarthritis Outcome Score, ${ }^{42}$ where we replaced the word 'knee' with 'back'.

\section{Psychological variables}

Kinesiophobia was measured using the Fear-Avoidance Beliefs Questionnaire-Physical Activity subscale (range 0-24, higher score indicates higher levels of kinesiophobia). ${ }^{43}$ Signs of depression were measured with the Centre for Epidemiological Studies-Depression questionnaire (range 0-60, higher score indicates more signs of depression). ${ }^{44}$ Pain catastrophising was measured using the Pain Catastrophising Scale (range 0-52, higher score indicates more pain catastrophising).$^{45}$ Beliefs and attitudes towards back pain was measured using the Back Beliefs Questionnaire (range 9-45, higher score indicates more positive beliefs) ${ }^{46}$ Start Back Screening Tool (SBT) was used to assess prognostic risk profiles. ${ }^{47}$ Expectations of recovery from back pain within the next 3 months was assessed with a five-point scale, with the categories 'fully recovered', 'much better', 'no difference', 'much worse' and 'worse than ever'.

\section{Clinical variables}

Pain with active movements was assessed for forward flexion, lateral flexion and rotation of the back. Physical performance with focus on trunk mobility was assessed with the 6-item Back Performance Scale (range 0-18, higher score indicates worse trunk mobility performance) ${ }^{48}$ Walking function was assessed with the TimedUp-and-Go (TUG) ${ }^{49}$ Signs of radiculopathy was measured using a clinical diagnostic model that summarises five items: Subjective sensory changes (1 point), radiating pain below the knee (2 points), leg pain worse than back pain (2 points), positive neural tension test (3 points) and neurological deficit of myotome, dermatome or reflexes in the lower limb (2 points) ${ }^{50}$ A score of $\geq 5 / 10$ has been shown to indicate $>80 \%$ probability of radiculopathy. ${ }^{50}$ Twelve red flags were assessed: Cancer, first episode of back pain, constant pain, unexplained weight loss, systemically unwell, fever, urinary retention or loss of bladder control, age $\geq 75$ years, trauma cause of back pain, osteoporosis, cortisone use and severe morning stiffness.

\section{Statistical analyses}

All analyses were performed using the IBM SPSS Statistics V.26 for Windows (IBM). To handle missing data, five multiple imputation datasets with 10 iterations were created using regression estimation, and the pooled estimates are presented in this study. Patient characteristics were described with counts and percentages for categorical variables, mean and SD for normally distributed continuous variables and median and IQR for continuous variables with a skewed distribution. Mann-Whitney U-test was used to assess differences in days between first primary care contact and inclusion to the study between primary care practitioners, and between those recruited from primary care and those recruited from media advertisements. Multinomial regression was used to assess the strength of the associations between patient characteristics and patient's choice of first primary care provider. First primary care provider (GP, PT or chiropractor) was the dependent variable. The chiropractic group was the largest, and therefore, chosen as the reference group. Patient characteristics were organised into five blocks, for which we created separate models: (1) sociodemographic, (2) general health, (3) current back pain episode and back pain history, (4) psychological variables and (5) clinical variables. All variables in the block were simultaneously included in the model, without univariate pretesting. The strength of associations is expressed as odds ratios (OR) with $95 \%$ CIs. We considered our study as exploratory, so no correction for multiple testing was performed.$^{51}$ Values of $\mathrm{p}<0.05$ were thus considered statistically significant. All tests were two sided.

\section{Assessment of generalisability}

Because of economic and practical reasons, we were unable to collect data on eligible participants that declined to participate or for other reasons were not invited. Therefore, we performed a descriptive comparison of the BACE-N on age, sex, nationality, educational level, work status, marital status, BMI, alcohol use, HR-QoL, depression and walking distance with individual data from a subsample from the study 'The Norwegian Study on Life Course, Ageing and Generation (NORLAG) ${ }^{52}{ }^{53}$ This study used a random sampling strategy in the general population and included 11028 participants. The subsample (NORLAG MSK) consisted of 794 participants collected in 2017. The participants of the subsample were $\geq 55$ years of age and had at least one musculoskeletal complaint.

\section{Sensitivity analyses}

We performed three sensitivity analyses: (1) To assess possible bias introduced by the multiple imputation procedure, the multiple multinomial regression analyses were performed on complete case data. We included a bootstrapping approach to assess the robustness of the coefficients. (2) Because PT services became available through direct access in Norway from 1 January 2018, characteristics of PT patients recruited before and after 
01.01.2018 were compared using individual sample t-tests or Mann-Whitney U-tests for continuous variables, and $\chi^{2}$ tests for categorical variables. (3) We performed the multiple multinomial regression analyses in the subgroup with low back pain only. Results from the sensitivity analyses are available in online supplemental material S1-S3.

\section{Sample size consideration}

Sample size was considered for the BACE-N study as a whole, with the following criteria: Having sufficient statistical power for up to 14 variables in a multivariate logistic regression analysis using the ' 10 events per variable' rule, ${ }^{54}$ with an outcome prevalence of $40 \%$, and allowing for a dropout-rate of $20 \%$. This yielded a preferred sample size of 450 participants. As the multinomial regression models in this study includes a maximum of 8 independent variables, we expect the sample size to be sufficient.

\section{Patient and public involvement}

Patient representatives were part of the scientific board of the study and involved in designing and establishing BACE-N. Results will be disseminated to the recruiting primary care providers and the participating patients in an annual newsletter.

\section{RESULTS}

A total of 452 patients were included in the study, 127 first visited a GP, 130 first visited a PT and 195 first visited a chiropractor. Eighteen patients were included from media advertisements. Median (IQR) number of days from first primary care contact to inclusion in the study was 13 (3-21) days for GP patients, 9 (3-21) for physiotherapy patients and 5 (1-13) for chiropractic patients. The duration was significantly shorter for chiropractic patients compared with GP patients $(\mathrm{p}<0.01)$ and PT patients $(p<0.01)$. There was no statistically significant difference in duration from first primary care contact to inclusion between those recruited directly from primary care practices (median (IQR) 7 (2-15) days), and those recruited through media advertisements (median (IQR) 16 (1-28) days) $(\mathrm{p}=0.315)$.

\section{Patient characteristics}

Missingness ranged from $0.0 \%$ to $16.8 \%$ for the variables, and total missingness was $4.4 \%$ across all values. Rates of missingness was similarly distributed across the primary care provider groups. Consult table 1 for details regarding patient characteristics. The median age of the patients was 66, around half of the patients were women, were in paid work, and had university-level education. Half of the patients had a hazardous alcohol consumption level, and nearly $60 \%$ of them were either current or previous smokers. One in six patients had experienced a fall during the last 6 weeks. Three out of four patients had one or more comorbidities.

Most patients reported moderate levels of back pain and moderate to severe levels of back-related disability with a median (IQR) RMDQ-score of 9 (5-13). Almost $70 \%$ of the patients experienced monthly or yearly recurrences of back pain. Over $40 \%$ experienced weekly sleep problems attributable to back pain, and $70 \%$ experienced moderate to extreme morning stiffness. Two thirds of the patients had a low-risk profile according to the SBT, and only $6.6 \%$ had a high-risk profile. Expectations of recovery were generally high, with three out of four expecting to be much better or fully recovered within 3 months.

\section{Associations between patient characteristics and type of first primary care provider}

Table 2 presents the associations from the multinomial regression analyses. Patients with higher back-related disability, longer duration of symptoms, worse physical performance, probable radiculopathy, poorer HR-QoL and lower expectations of being fully recovered within the next 3 months were more likely to visit a GP compared with a chiropractor. Patients with widespread pain were more likely to visit a chiropractor than a GP. The characteristics strongest associated with choosing a GP versus a chiropractor were duration of symptoms, widespread pain and expectation of being fully recovered.

Patients that were older, had a longer duration of symptoms, higher back-related disability, moderate morning stiffness, higher levels of pain catastrophising, worse physical performance, lower expectations of being fully recovered within the next 3 months were more likely to visit a PT compared with a chiropractor. Patients in the SBT medium or high risk group were more likely to visit a chiropractor compared with a PT. The characteristics strongest associated with choosing a PT versus a chiropractor were duration of symptoms and expectation of being fully recovered.

Gender, education level, marital status, employment status, comorbidities, back pain severity, sleep problems, kinesiophobia, depressive signs, back beliefs, red flags, pain on active range of motion and TUG-scores were not associated with type of primary care provider.

\section{Assessment of generalisability}

The BACE-N study sample had more men ( $48 \%$ vs $36.3 \%$ in NORLAG MSK), more participants with high educational level (44\% vs $28.6 \%$ in NORLAG MSK), more participants currently in paid work $(45.3 \%$ vs $31.6 \%$ in NORLAG MSK), and more participants living with a partner ( $76.8 \%$ vs $62.2 \%$ in NORLAG MSK). Age, nationality, alcohol consumption, BMI, depressive signs, HR-QoL and walking distance were similar for BACE-N and NORLAG MSK. See online supplemental material S4 for further details.

\section{DISCUSSION}

This study showed that nearly all older patients with back pain had experienced back pain previously, and for most patients this episode was the latest of a series of annually or monthly recurring episodes. This is in accordance with 
Table 1 Baseline characteristics of study participants $\uparrow$

\begin{tabular}{|c|c|c|c|c|c|}
\hline & Missing, n (\%) & Total $(n=452)$ & GP $(n=127)$ & PT $(n=130)$ & Chiro $(n=195)$ \\
\hline \multicolumn{6}{|l|}{ Sociodemographic variables } \\
\hline Age, median (IQR) & $0(0.0)$ & $66(59-72)$ & $67(60-73)$ & $68(63-74)$ & $63(58-71)$ \\
\hline Marital status & $19(4.2)$ & & & & \\
\hline Married or living with partner, $\mathrm{n}(\%)$ & & $347(76.8)$ & $90(70.1)$ & $98(74.6)$ & $158(81.0)$ \\
\hline Employment status & $5(1.1)$ & & & & \\
\hline Educational level, n (\%) & $20(4.4)$ & & & & \\
\hline Low (elementary +high school) & & $253(56.0)$ & $72(56.7)$ & $70(55.1)$ & $110(56.4)$ \\
\hline High (university level) & & $199(44.0)$ & $55(43.3)$ & $60(44.9)$ & $85(43.6)$ \\
\hline \multicolumn{6}{|l|}{ General health variables } \\
\hline Health-related quality of life (SF-36 0-100) & $41(9.1)$ & & & & \\
\hline Smoking status, n (\%) & $22(4.9)$ & & & & \\
\hline Current smoker & & $63(13.9)$ & $21(16.5)$ & $13(10.0)$ & $28(14.3)$ \\
\hline Previous & & 203 (44.9) & $59(46.4)$ & $60(46.2)$ & $84(43.1)$ \\
\hline Never & & $186(41.2)$ & $47(37.0)$ & $57(43.8)$ & $83(42.6)$ \\
\hline No of comorbidities (SCQ 0-15), median (IQR) & $18(4.0)$ & $1(1-2)$ & $1(0-2)$ & $2(1-2)$ & $1(1-5)$ \\
\hline BMI, mean (SD) & $14(3.1)$ & $27.6(4.7)$ & $27.6(4.5)$ & $27.5(4.7)$ & $27.7(4.8)$ \\
\hline Fall last 6 weeks, n (\%) & $24(5.3)$ & $73(16.1)$ & $13(10.2)$ & $24(18.4)$ & $35(18.2)$ \\
\hline Falls self-efficacy (FESI 16-64), mean (SD) & $48(10.6)$ & $21.8(6.0)$ & $22.4(6.3)$ & $22.2(6.1)$ & $21.1(5.7)$ \\
\hline Widespread pain, n (\%) & $16(3.5)$ & $33(7.3)$ & $5(4.0)$ & $7(5.3)$ & $21(10.8)$ \\
\hline Only once & & $15(3.3)$ & $4(3.1)$ & $6(4.6)$ & $4(2.1)$ \\
\hline Back pain location of current episode, $\mathrm{n}(\%)$ & $11(2.4)$ & & & & \\
\hline Thoracic only & & $19(4.2)$ & $4(3.1)$ & $7(5.4)$ & $8(4.1)$ \\
\hline Lumbar only & & $382(84.5)$ & $106(83.5)$ & $109(83.8)$ & $167(85.6)$ \\
\hline Both & & $51(11.3)$ & $17(13.4)$ & $14(10.8)$ & $20(10.3)$ \\
\hline Duration of current episode, $\mathrm{n}(\%)$ & $76(16.8)$ & & & & \\
\hline $0-6$ weeks & & $297(65.7)$ & $74(58.3)$ & $67(51.5)$ & $156(80.0)$ \\
\hline 6 weeks to 3 months & & $59(13.1)$ & $22(17.3)$ & $21(16.2)$ & $16(8.2)$ \\
\hline 3 months or over & & $96(21.2)$ & 31 (24.4) & 42 (32.3) & $23(11.8)$ \\
\hline Back pain severity (NRS 0-10), mean (SD) & $31(6.9)$ & $5.4(2.3)$ & $5.7(2.2)$ & $5.1(2.3)$ & $5.4(2.4)$ \\
\hline Back-related disability (RMDQ 0-24), median (IQR) & $45(10.0)$ & $9(5-13)$ & $10(6-14)$ & $9(6-13)$ & $8(3-13)$ \\
\hline Sleep problems due to back pain, $\mathrm{n}(\%)$ & $24(5.3)$ & & & & \\
\hline Weekly & & $189(41.8)$ & $60(47.2)$ & $49(37.7)$ & $80(41.0)$ \\
\hline Less than weekly & & $263(58.2)$ & $67(52.8)$ & $81(62.3)$ & $115(59.0)$ \\
\hline Morning stiffness, n (\%) & $26(5.8)$ & & & & \\
\hline Significant or extreme & & 178 (39.3) & $47(37.0)$ & $51(39.2)$ & $81(41.5)$ \\
\hline Moderate & & 144 (31.9) & $44(34.6)$ & 48 (36.9) & $51(26.2)$ \\
\hline Some or none & & $130(28.8)$ & $36(28.3)$ & $31(23.9)$ & 63 (32.3) \\
\hline
\end{tabular}




\begin{tabular}{|c|c|c|c|c|c|}
\hline & Missing, n (\%) & Total $(n=452)$ & GP $(n=127)$ & PT $(n=130)$ & Chiro $(n=195)$ \\
\hline \multicolumn{6}{|l|}{ Psychological variables } \\
\hline Kinesiophobia (FABQ-PA 0-24), median (IQR) & $18(4.0)$ & $10(5-14)$ & $11(6-14)$ & $10(5-15)$ & $9(3-13)$ \\
\hline Depression (CES-D 0-60), median (IQR) & $57(12.6)$ & $8(4-15)$ & $10(4-17)$ & $8.5(4-15)$ & $7(4-13)$ \\
\hline Pain catastrophising (PCS 0-52), median (IQR) & $35(7.7)$ & $10(4-16)$ & $11(5-18)$ & $12(5-18)$ & $7(3-14)$ \\
\hline Back beliefs (BBQ 9-45), mean (SD) & $57(12.6)$ & $29.8(7.0)$ & $28.0(6.9)$ & $29.3(7.2)$ & $31.3(6.7)$ \\
\hline Expectations for back pain next 3 months, n (\%) & $19(4.2)$ & & & & \\
\hline Fully recovered & & $115(25.4)$ & $19(15.0)$ & $24(18.5)$ & $72(36.9)$ \\
\hline Much better & & $226(50.0)$ & $66(52.0)$ & $71(54.6)$ & $89(45.6)$ \\
\hline No change or worse & & $111(24.6)$ & $42(33.0)$ & $35(26.9)$ & $33(16.9)$ \\
\hline Start Back Screening Tool risk profiles, $\mathrm{n}(\%)$ & $31(6.9)$ & & & & \\
\hline Low & & $297(65.7)$ & $72(56.7)$ & $92(70.8)$ & $133(68.2)$ \\
\hline Medium & & $125(27.7)$ & $38(29.9)$ & $32(24.6)$ & $55(28.2)$ \\
\hline High & & $30(6.6)$ & 16 (12.6) & $6(4.6)$ & $8(4.1)$ \\
\hline \multicolumn{6}{|l|}{ Clinical variables } \\
\hline Physical performance (BPS 0-18), median (IQR) & $20(4.4)$ & $5(2-8)$ & $7(3-9)$ & $5(3-8)$ & $4(1-7)$ \\
\hline Timed-Up-and-Go, mean seconds (SD) & $7(1.5)$ & $8.0(2.5)$ & $8.2(3.0)$ & $8.3(2.3)$ & $7.8(2.2)$ \\
\hline Positive diagnostic rule for radiculopathy, $\mathrm{n}(\%)$ & $38(8.4)$ & $99(22.0)$ & $37(29.1)$ & $31(23.8)$ & $31(15.9)$ \\
\hline No of red flags (0-12), median (IQR) & $50(11.0)$ & $1(0-2)$ & $1(0-2)$ & $1(0-2)$ & $1(0-1)$ \\
\hline Pain on active range of motion, $n(\%)$ & $9(2.0)$ & $295(65.3)$ & $86(67.7)$ & $88(67.7)$ & $120(61.5)$ \\
\hline
\end{tabular}

*AUDIT-C scores of $\geq 3 / 12$ for women and $\geq 4 / 12$ indicates hazardous alcohol consumption

†The presented characteristics are pooled estimates based on multiple imputation procedures.

AUDIT-C, Alcohol Use Disorder Identification Test-Consumption questions; BBQ, Back Beliefs Questionnaire; BPS, Back Performance Scale; CES-D, Centre for Epidemiological Studies-Depression; Chiro, chiropractor; FABQ-PA, Fear-Avoidance Beliefs Questionnaire-Physical Activity subscale; FES-I, Falls Self-Efficacy Scale-International; GP, general practitioner; NRS, Numeric Rating Scale; PCS, Pain Catastrophising Scale; PT, Physiotherapist; RMDQ, Roland-Morris Disability Questionnaire; SCQ, Self-administered Comorbidity Questionnaire; SF-36, Short Form Health Survey 36 Item.

several studies on back pain trajectories, where episodic or fluctuating pain was shown to be common both in the short and long term. ${ }^{55-58}$ Further, patients with more severe back-related disability and other symptoms and signs were overall more likely to visit a GP or a PT than a chiropractor. Contrary to this finding, patients with widespread pain were more likely to choose a chiropractor over a GP. This is the first study to assess associations of a broad range of patient characteristics and choice of first primary care provider in an older population. Older adults have previously been under-represented in back pain studies, ${ }^{34}$ and the evidence underlying treatment decisions in this age group may have been over-reliant on studies performed in younger populations. Thus, this study provides evidence to improve knowledge about older adults with back pain. This may prove important for clinical guideline development and informing stakeholders aiming to improve quality of care for older adults with back pain.

The burden of back pain and psychological profile were comparable between younger Norwegian back pain cohorts and the older BACE-N sample. ${ }^{59} 60$ The characteristics of the included patients in this study was largely comparable to the BACE-study from the Netherlands, ${ }^{1261}$ with a few exceptions. Both in our total study sample and our GP subsample, a larger proportion of patients had paid work, fewer experienced their first episode of back pain, and they reported lower levels of kinesiophobia and pain catastrophising compared with the Dutch study sample. When comparing our results to the Brazilian BACEstudy, ${ }^{12} 62$ the Brazilian study had a higher proportion of women. Further, our study sample had more patients in paid work, more patients with hazardous alcohol consumption patterns, more smokers, the patients had fewer comorbidities, lower levels of back-related disability and back pain severity, kinesiophobia, depression signs and pain catastrophising compared with the Brazilian BACE-sample. These differences between populations within the BACE consortium might be explained in part by minor differences in recruitment strategies in the different countries ${ }^{12}$ or differences in how primary care is organised in the different countries. In the Netherlands, patients were recruited exclusively from a GP setting, ${ }^{61}$ whereas in Brazil patients were recruited from primary care centres or health centres specialised in geriatrics. ${ }^{62}$ Another possible explanation may be cultural differences in the expression and interpretation of and coping with pain. ${ }^{63}$

In line with previous research on healthcare utilisation for back pain in younger populations, ${ }^{19}$ 21-23 25-28 our results suggest that patients with 'less complex' characteristics were more likely to visit a chiropractor compared with a GP or a PT. Unsurprisingly, studies using bivariate analyses $^{18} 2023252829$ to compare the provider groups find 
Table 2 Multinomial regression analyses; multivariate associations between patient characteristics and choice of healthcare provider (dependent variable) ${ }^{\star}$

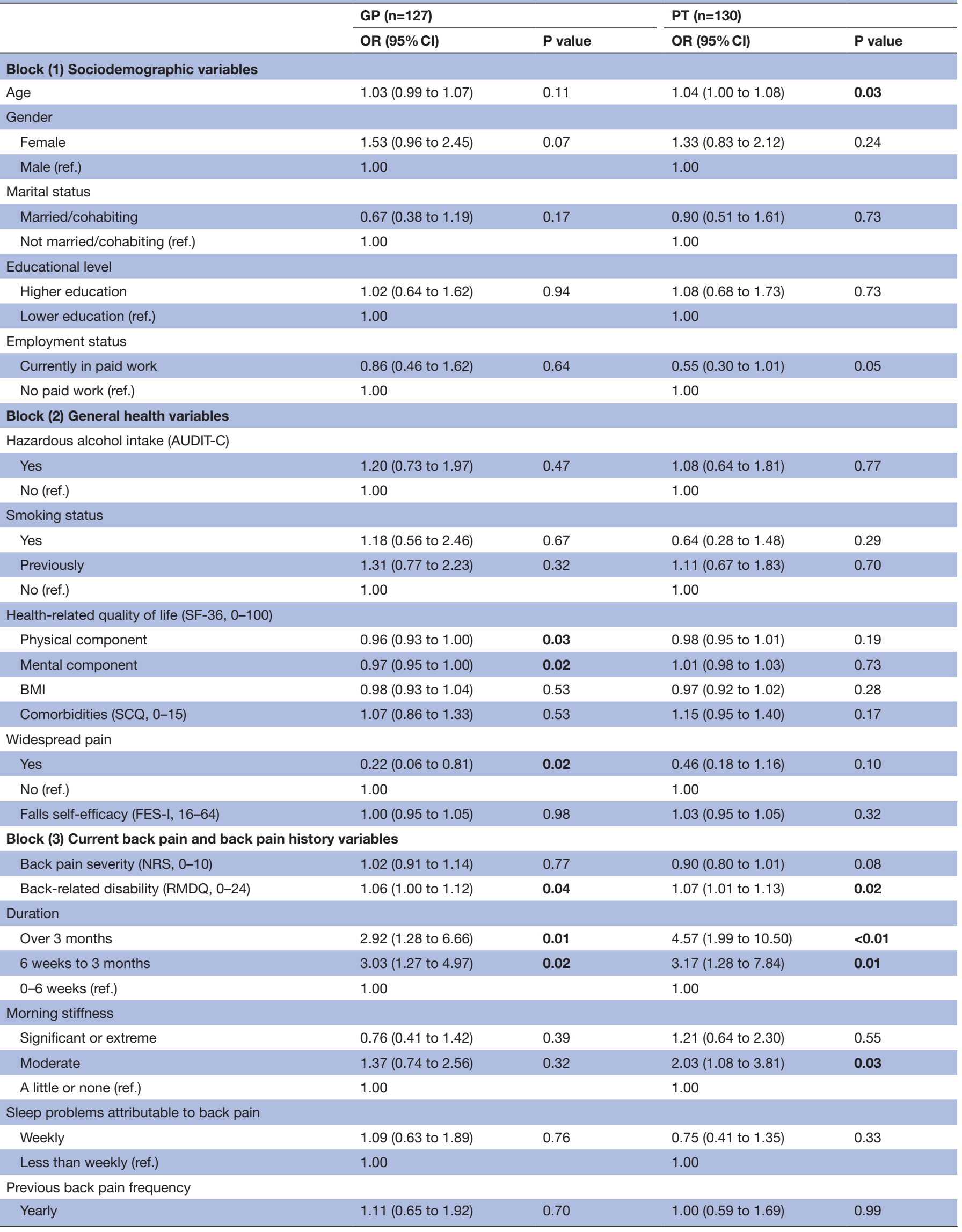


Table 2 Continued

\begin{tabular}{|c|c|c|c|c|}
\hline & \multicolumn{2}{|l|}{ GP $(n=127)$} & \multicolumn{2}{|l|}{ PT $(n=130)$} \\
\hline & OR $(95 \% \mathrm{Cl})$ & $P$ value & OR $(95 \% \mathrm{Cl})$ & $P$ value \\
\hline Not yearly (ref.) & 1.00 & & 1.00 & \\
\hline Fear-avoidance (FABQ-PA, 0-24) & 1.02 (0.98 to 1.07$)$ & 0.32 & 1.03 (0.98 to 1.08$)$ & 0.22 \\
\hline Pain catastrophising (PCS, 0-52) & 1.04 (1.00 to 1.07$)$ & 0.05 & 1.06 (1.02 to 1.10$)$ & $<0.01$ \\
\hline \multicolumn{5}{|l|}{ Expectation for back pain in 3 months } \\
\hline Recovered & $0.26(0.12$ to 0.56$)$ & $<0.01$ & 0.39 (0.19 to 0.79$)$ & 0.01 \\
\hline Much better & $0.65(0.35$ to 1.19$)$ & 0.16 & 0.85 (0.46 to 1.58$)$ & 0.61 \\
\hline No change or worse (ref.) & 1.00 & & 1.00 & \\
\hline \multicolumn{5}{|l|}{ Block (5) Clinical variables } \\
\hline No of red flags $(0-12)$ & 1.25 (0.99 to 1.58$)$ & 0.06 & 1.19 (0.96 to 1.48$)$ & 0.12 \\
\hline \multicolumn{5}{|l|}{ Diagnostic tool for radiculopathy } \\
\hline Positive & 1.94 (1.08 to 3.47$)$ & 0.03 & 1.52 (0.85 to 2.73$)$ & 0.16 \\
\hline Negative (ref.) & 1.00 & & 1.00 & \\
\hline \multicolumn{5}{|l|}{ Pain on active range of motion } \\
\hline Yes & 0.95 (0.57 to 1.58$)$ & 0.85 & $1.09(0.67$ to 1.80$)$ & 0.72 \\
\hline No (ref.) & 1.00 & & 1.00 & \\
\hline Trunk mobility performance (BPS, 0-18) & $1.16(1.08$ to 1.24$)$ & $<0.01$ & 1.07 (1.00 to 1.15$)$ & 0.04 \\
\hline Timed-Up-and-Go, mean seconds & 0.93 (0.83 to 1.04$)$ & 0.20 & $1.00(0.90$ to 1.11$)$ & 0.93 \\
\hline
\end{tabular}

The ORs for continuous variables represent the change in odds with a one-unit increase in the continuous variable.

The chiropractic group $(n=195)$ was the reference dependent variable.

Models were built block-wise within the five blocks: (1) sociodemographic (2) general health (3) current episode and back pain history (4) psychological and (5) clinical. All variables were included simultaneously.

Bold p-values identify associations that are statistically significant.

*The multinomial regression analyses are based on pooled estimates from multiple regression analyses.

AUDIT-C, Alcohol Use Disorder Identification Test - Consumption questions; BBQ, Back Beliefs Questionnaire; BMI, body mass index; BPS, Back Performance Scale; CES-D, Centre for Epidemiological Studies-Depression; FABQ-PA, Fear-Avoidance Beliefs Questionnaire-Physical Activity subscale; FES-I, Falls Self-Efficacy Scale-International; GP, general practitioner; NRS, Numeric Rating Scale; PCS, Pain Catastrophising Scale; PT, physiotherapist; ref, reference category; RMDQ, Roland-Morris Disability Questionnaire; SCQ, Self-administered Comorbidity Questionnaire; SF-36, Short Form Health Survey 36 Item.

more significant associations or differences than studies using multivariate analyses. ${ }^{19} 21222627$ However, regardless of statistical approach, these studies suggest that patients who seek chiropractic care have an overall lower burden of back pain compared with patients seeking GP or PT care. ${ }^{18-2325}$ One notable exception is the study of Eklund et $a l,{ }^{24}$ which found that Swedish chiropractic patients had more pain and worse psychological and behavioural characteristics compared with a sample of sick-listed primary care (specific provider unknown) patients at high risk for chronicity. Our finding showing that patients with widespread pain were more likely to choose a chiropractor over a GP was contrary to the general pattern of chiropractic patients being less 'complex.' To the best of our knowledge, no previous studies have compared prevalence of widespread pain in the two populations, but one study showed that GP patients had more musculoskeletal comorbidities, ${ }^{25}$ possibly implying more widespread pain. Two previous studies found an association between higher age and odds of seeking care from a PT compared with a chiropractor, ${ }^{26} 27$ in line with our results.

Many of the patient characteristics associated with choice of primary care provider in this study have previously been found to be significant prognostic factors for persistent back-related disability and back pain in older people. For example, duration of back pain and expectation of improvement, ${ }^{64-69}$ and higher levels of back-related disability, ${ }^{65-70}$ are consistently reported as significant prognostic factors for a poor outcome of a back pain episode. A few studies in older people have found that single symptoms of neurological involvement such as leg pain below the knee, and the diagnosis of spinal stenosis were prognostic factors for the outcome of a back pain episode. ${ }^{6467}$ We combined single symptoms of neurological involvement into a compound measure, but it is likely that older patients with radiculopathy have worse outcomes than those without radiculopathy. Although slightly different from widespread pain, the 
presence of multisite pain has also in some studies been found to be a prognostic factor for the outcome of back pain in older adults. ${ }^{67}$ The impact of pain catastrophising on the clinical course of back pain is less clear in older adults ${ }^{66}{ }^{69}$ compared with younger populations, ${ }^{72}$ but it is not unreasonable to believe that pain catastrophising may be a prognostic factor for back pain in older adults. Thus, the associations between potential prognostic factors and choice of first primary care provider imply that we can expect the clinical course of patients in the three primary care groups to be different. Further, they imply that caution should be exercised when generalising across primary care populations.

The results of this study need to be viewed with consideration of some limitations. We instructed the recruiting primary care providers to invite consecutive patients, but because of obvious time constraints in clinical practice we could not ask them to keep record of how many declined to participate, nor of eligible patients that were not invited. This recruitment strategy increases the risk of selection bias, and thus could reduce the external validity of the study. To compensate for this limitation, we compared the BACE-N sample with the NORLAG musculoskeletal subsample. The characteristics of the two samples were largely comparable, but BACE-N has more men, more participants with higher education, more in paid work, and more living with their partner. Sex and education level have previously been shown to be associated with back pain severity and back-related disability in older adults. ${ }^{12} 13$ Thus, it may be possible that the levels of back pain and back-related disability presented in this study are slightly underestimated. The NORLAG musculoskeletal subsample is sampled from the general population, which may not be representative of those who seek care. However, the most important determinants of care-seeking for back pain seems to be pain severity and disability levels. ${ }^{73} \mathrm{We}$, therefore, believe the assessment to be justified.

Another limitation may be the analysis strategy. We chose to keep the variables in the five blocks to provide a broad assessment of the differences in casemix in the three primary care settings. To limit the number of statistical tests performed, univariate pre-testing and testing a 'final model' across blocks was avoided. Furthermore, a different organisation of the variables, for example, strictly adhering to the biopsychosocial model ${ }^{74}$ or Andersen's behavioural model of health services use ${ }^{75}$ may have yielded slightly different results. However, our results are largely supported by previous studies, so the potential differences because of analysis strategy or variable organisation may be negligible. A third limitation is that we were unable to examine some possibly important determinants for healthcare use, such as access to different providers, patient's familiarity with providers, the patient's economic situation and social network referrals. ${ }^{75-77}$ These factors may be the most important determinants in driving the patient's choice of first primary care provider, and including these factors would have given an even broader overview of associations between individual and contextual characteristics and choice of primary care provider. We suggest that future research focus on examining the contextual and social factors associated with healthcare service use. Finally, generalisation of our results to other healthcare systems may be limited. Different healthcare systems may have different access to care, different payment schemes and different professional training and responsibilities for the healthcare providers, all of which may impact health services utilisation and consequently the patient characteristics associated with choosing different primary care provides. ${ }^{75} 7879$

\section{CONCLUSION}

We found that nearly all older adults with back pain seeking primary care had experienced back pain previously, and recurring episodes were common. In general, patients with more severe back-related disability and other clinical symptoms and signs were more likely to visit a GP or a PT than a chiropractor. Our results suggest that important patient characteristics are associated with older adult's choice of primary care providers due to back pain, which may affect the clinical course of back pain for these patients. The findings highlight the need for caution with generalisation of study results across primary care populations. This is an important consideration for healthcare providers, for the development and implementation of clinical practice guidelines, and for regulators when developing primary care pathways for back pain. Further research is needed in assessing if the choice of primary care provider affects future care pathways and the clinical course of back pain in older adults.

\section{Twitter Ørjan Nesse Vigdal @orjanvigdal}

Acknowledgements The authors thank all study participants for their significant contribution. Further, we would like to thank all the recruiting healthcare providers: Kerstin Ulrich, Lise Lothe, Tim Raven, Andreas Hoff Nordvik, Christoffer Børsheim, Steinar Forshei, Mette Brekke, Daniel Major, Jan Harald Lønn, Agnes Mordt, Andrea Kolstad, Mathias Svanevik, Alexander Diesen, Lars Gullestad, Ida Svalstuen, Joakim Ordahl, Mona Øversveen, Jørgen Kongtorp, Are Hansen, Geir Haram, Palwinder Singh, Svein Erik Sandelien, Bent Ulseth, Harald Nordheim, Ola Sand, Ragnhild Perstølen, Jorun Salater, Anna AllenUnhammer, Morten Nilsen, Haakon Lilleeng Asmyhr, Philip Wilkens, Ane Klevberg, Eli Magnesen, Aleksander Killingmo, Bjørn Tore Bjørkedal, Stina Lund, Daniel Ekeberg, Berte Marie Enger, Johan Edvard Tellum, Morten de la Cruz, Bård Kvam, Marte Paulsen, Astrid Figger, Christian Mayer, Trond Magne Aasberg, Thea Tømmervåg, Jørgen Øyen, Håvard Nordås, Tore Viste Ollestad, Olav Aase, Renate Meier, Bjørn Røe, Jørgen Øyen, Jack Johnson, Carl-Erik Høgquist, Ingrid Hystad, Mats Thorbeck, Elisabeth Barø, Kaja McCormick, Lars Martin Fischer, Martin Haagensen, Cathrine Rossland, Marianne Storberget, Nora Helk, Grete Bråten, Annecken Lister Haugen, Hege Herstad, Cathrine Natland, Frøydis Blaker Åsbø, Ola Klaastad, Thorleif Henning Monsen, Geir Wiik, Jørn Christian Halvorsen, Tonje Høgdahl Mysen, Tine Tandberg, Eir Marie Bergan, Rune Solheim, Ole Kristoffer Larsen. We thank the research assistants for assisting with clinical examinations and providing baseline questionnaires to study participants. We thank the BACE-N scientific board, and the BACE Consortium for important input with designing the study.

Contributors $\emptyset \mathrm{NV}$ : study design, data collection, data analyses, manuscript draft. KS: study design, data interpretation, critical revision. RMK: data collection, data interpretation, critical revision. MCS: Statistical advisor, data interpretation, critical revision. MG: principal investigator, study design, data interpretation, critical revision. 
Funding This work was funded by The Norwegian Fund for Post-Graduate Training in Physiotherapy (grant number 90749).

Disclaimer The funding body was not involved in designing the study, data collection, analyses or interpretation of data, nor in writing the manuscript.

Competing interests None declared.

Patient consent for publication Not applicable.

Ethics approval The study was classified as a quality assessment study by the Norwegian Regional Committee for Medical Research Ethics (reference no. 2014/1634/REK vest) and was approved by the Norwegian Social Science Data Service in 2015 (reference no. 42149).

Provenance and peer review Not commissioned; externally peer reviewed.

Data availability statement No data are available. All data relevant to the study are included in the article or uploaded as online supplemental information.

Supplemental material This content has been supplied by the author(s). It has not been vetted by BMJ Publishing Group Limited (BMJ) and may not have been peer-reviewed. Any opinions or recommendations discussed are solely those of the author(s) and are not endorsed by BMJ. BMJ disclaims all liability and responsibility arising from any reliance placed on the content. Where the content includes any translated material, BMJ does not warrant the accuracy and reliability of the translations (including but not limited to local regulations, clinical guidelines, terminology, drug names and drug dosages), and is not responsible for any error and/or omissions arising from translation and adaptation or otherwise.

Open access This is an open access article distributed in accordance with the Creative Commons Attribution Non Commercial (CC BY-NC 4.0) license, which permits others to distribute, remix, adapt, build upon this work non-commercially, and license their derivative works on different terms, provided the original work is properly cited, appropriate credit is given, any changes made indicated, and the use is non-commercial. See: http://creativecommons.org/licenses/by-nc/4.0/.

\section{ORCID iDs}

Ørjan Nesse Vigdal http://orcid.org/0000-0001-5075-7720

Margreth Grotle http://orcid.org/0000-0001-8243-1143

\section{REFERENCES}

1 Vos T, Flaxman AD, Naghavi M, et al. Years lived with disability (YLDs) for 1160 sequelae of 289 diseases and injuries 1990-2010: a systematic analysis for the global burden of disease study 2010 . The Lancet 2012;380:2163-96.

2 Hoy D, Bain C, Williams G, et al. A systematic review of the global prevalence of low back pain. Arthritis Rheum 2012;64:2028-37.

3 Bressler HB, Keyes WJ, Rochon PA, et al. The prevalence of low back pain in the elderly. a systematic review of the literature. Spine 1999:24:1813-9.

4 Paeck T, Ferreira ML, Sun C, et al. Are older adults missing from low back pain clinical trials? a systematic review and meta-analysis. Arthritis Care Res 2014:66:1220-6.

5 Jarvik JG, Comstock BA, Bresnahan BW, et al. Study protocol: the back pain outcomes using longitudinal data $(B O L D)$ registry. $B M C$ Musculoskelet Disord 2012;13:64.

6 Scheele J, Luijsterburg PAJ, Ferreira ML, et al. Back complaints in the elders (BACE); design of cohort studies in primary care: an international Consortium. BMC Musculoskelet Disord 2011;12:193.

7 Kalichman L, Cole R, Kim DH, et al. Spinal stenosis prevalence and association with symptoms: the framingham study. Spine $J$ 2009;9:545-50.

8 Van der Klift M, De Laet CEDH, McCloskey EV, et al. The incidence of vertebral fractures in men and women: the rotterdam study. $J$ Bone Miner Res 2002;17:1051-6.

9 de Schepper EIT, Damen J, van Meurs JBJ, et al. The association between lumbar disc degeneration and low back pain: the influence of age, gender, and individual radiographic features. Spine 2010;35:p. 531-536.

10 Enthoven WTM, Geuze J, Scheele J. Prevalence and "red flags" regarding specified causes of back pain in older adults presenting in general. Phys Ther 2016;96:305-12.

11 Enthoven WTM, Scheele J, Bierma-Zeinstra SMA, et al. Back complaints in older adults: prevalence of neuropathic pain and its characteristics. Pain Med 2013:14:1664-72.

12 Jesus-Moraleida FR, Ferreira PH, Ferreira ML, et al. Back complaints in the elders in Brazil and the Netherlands: a cross-sectional comparison. Age Ageing 2017;46:476-81.
13 Jarvik JG, Comstock BA, Heagerty PJ, et al. Back pain in seniors: the back pain outcomes using longitudinal data (BOLD) cohort baseline data. BMC Musculoskelet Disord 2014;15:1-23.

14 Kinge JM, Knudsen AK, Skirbekk V, et al. Musculoskeletal disorders in Norway: prevalence of chronicity and use of primary and specialist health care services. BMC Musculoskelet Disord 2015;16:1-9.

15 Werner EL, Indahl A. Kunnskap, praksis OG holdninger TIL rygglidelser HOS leger, fysioterapeuter OG kiropraktorer. Tidsskr Nor Laegeforen 2005;125:1794-7 https://tidsskriftet.no/2005/06/ originalartikkel/kunnskap-praksis-og-holdninger-til-rygglidelser-hosleger-fysioterapeuter

16 Fritz JM, Kim J, Dorius J. Importance of the type of provider seen to begin health care for a new episode low back pain: associations with future utilization and costs. J Eval Clin Pract 2016;22:247-52.

17 Kazis LE, Ameli O, Rothendler J, et al. Observational retrospective study of the association of initial healthcare provider for new-onset low back pain with early and long-term opioid use. BMJ Open 2019;9:e028633.

18 Carey TS, Evans AT, Hadler NM, et al. Acute severe low back pain. a population-based study of prevalence and care-seeking. Spine 1996;21:339-44.

19 Hurwitz EL, Morgenstern $\mathrm{H}$. The effects of comorbidity and other factors on medical versus chiropractic care for back problems. Spine 1997;22:2254-63.

20 Nyiendo J, Haas M, Goldberg B, et al. Patient characteristics and physicians' practice activities for patients with chronic low back pain: A practice-based study of primary care and chiropractic physicians. J Manipulative Physiol Ther 2001;24:92-100.

21 Côté P, Cassidy JD, Carroll L. The treatment of neck and low back pain: who seeks care? who goes where? Med Care 2001;39:956-67.

22 Sharma R, Haas M, Stano M. Patient attitudes, insurance, and other determinants of self-referral to medical and chiropractic physicians. Am J Public Health 2003;93:2111-7.

23 Hestbaek L, Munck A, Hartvigsen L, et al. Low back pain in primary care: a description of 1250 patients with low back pain in Danish general and chiropractic practice. Int J Family Med 2014;2014:106102.

24 Eklund A, Bergström G, Bodin L, et al. Psychological and behavioral differences between low back pain populations: a comparative analysis of chiropractic, primary and secondary care patients. BMC Musculoskelet Disord 2015:16:306.

25 Hartvigsen L, Kongsted A, Vach W, et al. Baseline characteristics may help indicate the best choice of health care provider for back pain patients in primary care: results from a prospective cohort study. J Manipulative Physiol Ther 2020;43:13-23.

26 Chevan J, Riddle DL. Factors associated with care seeking from physicians, physical therapists, or chiropractors by persons with spinal pain: a population-based study. J Orthop Sports Phys Ther 2011:41:467-76.

27 Blanchette M-A, Rivard M, Dionne CE, et al. Workers' characteristics associated with the type of healthcare provider first seen for occupational back pain. BMC Musculoskelet Disord 2016;17:428.

28 Sibbritt D, Lauche R, Sundberg T, et al. Severity of back pain may influence choice and order of practitioner consultations across conventional, allied and complementary health care: a cross-sectional study of 1851 mid-age Australian women. BMC Musculoskelet Disord 2016;17:393.

29 Walker BF, Muller R, Grant WD. Low back pain in Australian adults. health provider utilization and care seeking. J Manipulative Physiol Ther 2004;27:327-35.

30 Saunes S. Norway: health system review, 2020. Available: https:// apps.who.int/iris/handle/10665/330299

31 Loge JH, Kaasa S. Short form 36 (SF-36) health survey: normative data from the general Norwegian population. Scand J Soc Med 1998;26:250-8.

32 Bush K. The audit alcohol consumption questions (AUDIT-C): an effective brief screening test for problem drinking. Arch Intern Med 1998;158:1789.

33 Bradley KA, DeBenedetti AF, Volk RJ, et al. AUDIT-C as a brief screen for alcohol misuse in primary care. Alcohol Clin Exp Res 2007;31:1208-17.

34 Norwegian National advisory unit on concurrent substance abuse and mental health disorders. Available: https://rop.no/ kartleggingsverktoey/audit-c/

35 Sangha O, Stucki G, Liang MH, et al. The self-administered comorbidity questionnaire: a new method to assess comorbidity for clinical and health services research. Arthritis Rheum 2003:49:156-63.

36 Wolfe F, Butler SH, Fitzcharles M, et al. Revised chronic widespread pain criteria: development from and integration with fibromyalgia criteria. Scand J Pain 2019;20:77-86. 
37 Melzack R. The McGill pain questionnaire: major properties and scoring methods. Pain 1975;1:277-99.

38 Helbostad JL, Taraldsen K, Granbo R, et al. Validation of the falls efficacy scale-International in fall-prone older persons. Age Ageing 2010;39:259.

39 Von Korff M, Jensen MP, Karoly P. Assessing global pain severity by self-report in clinical and health services research. Spine 2000;25:3140-51.

40 Grotle M, Brox JI, Vøllestad NK. Cross-cultural adaptation of the Norwegian versions of the roland-morris disability questionnaire and the Oswestry disability index. J Rehabil Med 2003;35:241-7.

41 Buysse DJ, Reynolds CF, Monk TH, et al. The pittsburgh sleep quality index: a new instrument for psychiatric practice and research. Psychiatry Res 1989;28:193-213.

42 Roos EM, Roos HP, Lohmander LS, et al. Knee injury and osteoarthritis outcome score (KOOS)--development of a selfadministered outcome measure. J Orthop Sports Phys Ther 1998;28:88-96

43 Grotle M, Brox JI, Vøllestad NK. Reliability, validity and responsiveness of the fear-avoidance beliefs questionnaire: methodological aspects of the Norwegian version. J Rehabil Med 2006;38:346-53.

44 Radloff LS. The CES-D scale: a self report depression scale for research in the general population. Applied Psychological Measurements 1977;1:385-401.

45 Fernandes L, Storheim K, Lochting I, et al. Cross-cultural adaptation and validation of the Norwegian pain catastrophizing scale in patients with low back pain. BMC Musculoskelet Disord 2012;13:111.

46 Tingulstad A, Munk R, Grotle M, et al. Back beliefs among elderly seeking health care due to back pain; psychometric properties of the Norwegian version of the back beliefs questionnaire. BMC Musculoskelet Disord 2019;20:510.

47 Hill JC, Dunn KM, Lewis M, et al. A primary care back pain screening tool: identifying patient subgroups for initial treatment. Arthritis Rheum 2008;59:632-41

48 Strand LI, Moe-Nilssen R, Ljunggren AE. Back performance scale for the assessment of mobility-related activities in people with back pain. Phys Ther 2002;82:1213-23.

49 Podsiadlo D, Richardson S. The timed "up \& go": a test of basic functional mobility for frail elderly persons. J Am Geriatr Soc 1991;39:142-8.

50 Stynes S, Konstantinou K, Ogollah R, et al. Clinical diagnostic model for sciatica developed in primary care patients with low back-related leg pain. PLoS One 2018;13:e0191852.

51 Bender R, Lange S. Adjusting for multiple testing--when and how? J Clin Epidemiol 2001;54:343-9.

52 Slagsvold B, Veenstra M, Daatland SO, et al. Life-course, ageing and generations in Norway:the NorLAG study. Nor Epidemiol 2012;22

53 Torsteinsen A, Holmøy A. Den norske studien AV livsløp, aldring OG generasjon-tredje runde (NorLAG3). Dokumentasjonsrapport 2019 https://ssb.brage.unit.no/ssb-xmlui/handle/11250/2626118

54 Moons KGM, Royston P, Vergouwe $\mathrm{Y}$, et al. Prognosis and prognostic research: what, why, and how? BMJ 2009;338:b375.

55 Dunn KM, Jordan K, Croft PR. Characterizing the course of low back pain: a latent class analysis. Am J Epidemiol 2006;163:754-61.

56 Dunn KM, Campbell P, Jordan KP. Long-term trajectories of back pain: cohort study with 7-year follow-up. BMJ Open 2013;3:e003838.

57 Kongsted A, Kent P, Hestbaek L, et al. Patients with low back pain had distinct clinical course patterns that were typically neither complete recovery nor constant pain. a latent class analysis of longitudinal data. Spine J 2015;15:885-94.

58 Kongsted A, Kent P, Axen I, et al. What have we learned from ten years of trajectory research in low back pain? BMC Musculoskelet Disord 2016;17:1-11.
59 Nordstoga AL, Vasseljen O, Meisingset I, et al. Improvement in work ability, psychological distress and pain sites in relation to low back pain prognosis: a longitudinal observational study in primary care. Spine 2019;44:E423-9.

60 Grotle M, Brox JI, Glomsrød B, et al. Prognostic factors in firsttime care seekers due to acute low back pain. Eur J Pain 2007:11:290-8.

61 Scheele J, Enthoven WTM, Bierma-Zeinstra SMA, et al. Characteristics of older patients with back pain in general practice: BACE cohort study. Eur J Pain 2014;18:279-87.

62 Jesus-Moraleida FRD, Ferreira PH, Ferreira ML, et al. The Brazilian back complaints in the elders (Brazilian BACE) study: characteristics of Brazilian older adults with a new episode of low back pain. Braz $J$ Phys Ther 2018;22:55-63.

63 Peacock S, Patel S. Cultural influences on pain. Rev Pain 2008;1:6-9.

64 Scheele J, Enthoven WTM, Bierma-Zeinstra SMA, et al. Course and prognosis of older back pain patients in general practice: a prospective cohort study. Pain 2013;154:951-7.

65 Deyo RA, Bryan M, Comstock BA, et al. Trajectories of symptoms and function in older adults with low back disorders. Spine 2015:40:1352-62.

66 Enthoven WTM, Koes BW, Bierma-Zeinstra SMA, et al. Defining trajectories in older adults with back pain presenting in general practice. Age Ageing 2016;45:878-83.

67 Rundell SD, Sherman KJ, Heagerty PJ, et al. Predictors of persistent disability and back pain in older adults with a new episode of care for back pain. Pain Med 2017;18:1049-62.

68 Jarvik JG, Gold LS, Tan K, et al. Long-term outcomes of a large, prospective observational cohort of older adults with back pain. Spine J 2018;18:1540-51.

69 van der Gaag WH, Chiarotto A, Heymans MW, et al. Developing clinical prediction models for nonrecovery in older patients seeking care for back pain: the back complaints in the elders prospective cohort study. Pain 2021;162:1632-40.

70 van den Berg R, Chiarotto A, Enthoven WT, et al. Clinical and radiographic features of spinal osteoarthritis predict long-term persistence and severity of back pain in older adults. Ann Phys Rehabil Med 2020:101427.

71 Rundell SD, Patel KV, Krook MA, et al. Multi-Site pain is associated with long-term patient-reported outcomes in older adults with persistent back pain. Pain Med 2019;20:1898-906.

72 Wertli MM, Eugster R, Held U, et al. Catastrophizing-a prognostic factor for outcome in patients with low back pain: a systematic review. Spine J 2014;14:2639-57.

73 Ferreira ML, Machado G, Latimer J, et al. Factors defining careseeking in low back pain--a meta-analysis of population based surveys. Eur J Pain 2010;14:747.e1-747.e7.

74 Waddell G. 1987 Volvo award in clinical sciences. a new clinical model for the treatment of low-back pain. Spine 1987;12:632-44.

75 Andersen RM. National health surveys and the behavioral model of health services use. Med Care 2008;46:647-53.

76 Davis MA, Yakusheva O, Gottlieb DJ, et al. Regional supply of chiropractic care and visits to primary care physicians for back and neck pain. J Am Board Fam Med 2015;28:481-90.

77 Kirby ER, Broom AF, Adams J, et al. A qualitative study of influences on older women's practitioner choices for back pain care. BMC Health Serv Res 2014;14:131.

78 Garrity B, McDonough C, Ameli O, et al. Unrestricted direct access to physical therapist services is associated with lower health care utilization and costs in patients with new-onset low back pain. Phys Ther 2019.

79 Carey K, Ameli O, Garrity B, et al. Health insurance design and conservative therapy for low back pain. Am J Manag Care 2019;25:e182-7. 